\title{
Alzheimer's disease candidate gene PION is differentially expressed in human prefrontal cortex
}

\author{
Min Zhu, David Saffen ${ }^{*}$ \\ From 2011 International Conference on Molecular Neurodegeneration \\ Shanghai, China. 22-24 September 2011
}

\begin{abstract}
Background
PION (Pigeon homologue protein), located on chromosome 7q11.23, encodes gSAP (gamma-secretase activating protein), which is cleaved to form a $16 \mathrm{kDa} C$ terminal fragment (gSAP-16K) that interacts with gamma-secretase to facilitate the cleavage of amyloid precursor protein-beta-C-terminal fragment (APP-beta$\mathrm{CTF}$ ), releasing the neurotoxic peptide A-beta $[\mathrm{He} \mathrm{G}$, et al, Nature 2010]. The study by He G, el al. also demonstrated that partial siRNA-mediated inhibition of gSAP expression in $\mathrm{N} 2$ a cells reduces A-beta production, suggesting that gSAP-16K modulates APP-beta-CTF cleavage in a dose-dependent manner. Taken together, these observations suggest that levels of PION gene expression in human brain may also affect levels of A-beta production and thereby influence the risk of developing Alzheimer's disease. The goal of the present study is to quantify variation of PION mRNA expression in human prefrontal cortex and identify haplotypes and/or combinations of genotypes that predict high- or low-levels of mRNA expression.
\end{abstract}

\section{Methods}

Sixty-four independent frozen sections of prefrontal cortex (Han Chinese autopsy samples; Brodmann area 46) were obtained from the China Brain Bank Center (Wuhan, China). Genomic DNA and total RNA were isolated using standard techniques. A common SNP, rs2037753 (heterozygosity $=0.422$ ), located within exon 16 of PION mRNA was chosen as a molecular marker to distinguish mRNAs derived from each autosomal allele. SNaPShot ${ }^{\odot}$-based AEI assays were carried out as

\footnotetext{
* Correspondence: saffen@fudan.edu.cn

Institutes of Brain Science, State Key Laboratory for Medical Neurobiology,

School of Life Science, Fudan University, China
}

previously described [Lim JE, Molecular Psychiatry, 2007]. Analysis of population distributions of $\log _{2} \mathrm{AEI}$ ratios was carried out using a mathematical model developed in-house. Levels of PION mRNA relative to mRNA encoding the house-keeping gene GAPDH were quantified by real-time PCR (calculated as $\triangle \mathrm{Ct}$ ). Genomewide genotyping of all the above samples was carried out using HumanOmni1-Qad arras (Illumina) arrays. SNPs with genotypes that correlate with relative expression of PION mRNA were identified by linear regression analysis for SNPs within a 205,650 base pair region of chromosome 7 centered on PION.

\section{Results}

We observed robust allele-specific expression of PION mRNA in approximately 24 out of 34 samples heterozygous for the marker SNP. Mathematical modeling of the $\log _{2} \mathrm{AEI}$ population distributions predicted that PION mRNA expression is controlled by three cis-acting regulatory elements, one of which is in partial linkage disequilibrium with the marker SNP. Scanning SNPs in the region of the PION gene for correlations with mRNA expression revealed a single SNP, rs10271991 (located in intron 22), that is highly correlated with mRNA expression $(\mathrm{r} 2=23.5 ; \mathrm{P}=0.0001)$. Comparison between a model that includes rs10271991 (Major allele frequency $=0.51$; D' with marker SNP $=0.8$ ) and experimentally determined $\log _{2}$ AEI distributions yielded excellent agreement $\left(\mathrm{r}^{2}=0.96\right)$. According to this model, the remaining two variants that control expression of PION mRNA are both predicted to have major allele frequencies of approximately 0.8 and to be unlinked to the marker SNP (i.e., D' = 0). 


\section{Conclusions}

We have used real-time PCR-based measurements of relative mRNA expression in human prefrontal cortex and genotyping to identify a SNP within the PION gene that correlates with mRNA expression. Our modeling of population distributions of $\log _{2}$ AEI ratios predicts that PION mRNA expression is controlled by a variant linked to this SNP plus two additional variants that remain to be identified.

Published: 7 February 2012

doi:10.1186/1750-1326-7-S1-S25

Cite this article as: Zhu and Saffen: Alzheimer's disease candidate gene PION is differentially expressed in human prefrontal cortex. Molecular

Neurodegeneration 2012 7(Suppl 1):S25.

Submit your next manuscript to BioMed Central and take full advantage of:

- Convenient online submission

- Thorough peer review

- No space constraints or color figure charges

- Immediate publication on acceptance

- Inclusion in PubMed, CAS, Scopus and Google Scholar

- Research which is freely available for redistribution 